\title{
Genetic Polymorphisms of CYP2C19 and Resistance to Clopidogrel Therapy among Iranian Patients Suffering from Ischemic Heart Disease
}

\author{
Behzad Poopak ${ }^{1 *}$, Maed Heidari ${ }^{1}$, Parviz Fallah ${ }^{2}$, Nazila Safari ${ }^{3}$, Saghar Rabieipour ${ }^{3}$, Zahra Amiri ${ }^{1}$, Shahram Taghdisi ${ }^{1}$ \\ ${ }^{1}$ Department of Hematology, Islamic Azad University, Tehran Medical Sciences Branch, Tehran, Iran. \\ ${ }^{2}$ School of Medicine, Islamic Azad University, Tehran Medical Sciences Branch, Tehran, Iran. \\ ${ }^{3}$ Department of Hematology, Alborz University of Medical Sciences, Alborz, Iran. \\ ${ }^{4}$ Payvand Clinical and Specialty Laboratory, Tehran, Iran. \\ ${ }^{5}$ School of Science, Islamic Azad University, Tehran Medical Sciences Branch, Tehran, Iran.
}

Received: 1 Apr 2016

Revised : 6 May 2016

Accepted: 19 May 2016

Corresponding Author: Behzad Poopak

Islamic Azad University, Tehran

Medical Sciences Branch, Tehran, Iran

Phone: 09121196422

E-mail: bpoopak@gmail.com

\begin{abstract}
Background: Clopidogrel is a standout amongst the most ordinarily recommended medications to avoid ischemic occasions taking after coronary disorder or stant position. However, impaired responses the therapy as well as resistance to the therapy have also been reported. Genetic variants play an important role in clopidogrel biotransformation of its active metabolite that may subsequently influence the antiplatelet effect of clopidogrel. The objective of this study was to evaluate the prevalence of the cytochrome P450 (CYP450) 2C19 enzyme (CYP2C19) genotypes which are involved in the activation of clopidogrel in a random Iranian population of various ethnic groups (Persian, Azari, Kurd, etc.). Molecular analysis of CYP2C19 polymorphisms may be helpful in the determination of optimal antiplatelet therapy.

Materials and Methods: CYP2C19 $(* 1 / * 2 / * 3)$ variants were assessed by Polymerase Chain Reaction-Restriction Length Polymorphism (PCR-RFLP) assays in a representative sample of 154 Iranian patients with ischemic heart disease.

Results: The frequencies of CYP2C19*1 (normal genotype), *2 (heterozygote) and *3 (homozygote) were $112(72.7 \%), 36(23.4 \%)$ and $6(3.9 \%)$, respectively.

Conclusion: The United States Food and Drug Administration (FDA) recommendations are more useful to be practiced in our country compared with other countries. Physicians should identify poor metabolizers for consideration of other antiplatelet medications or alternative dosing strategies.
\end{abstract}

Keywords: Clopidogrel; Ischemic heart disease; CYP2C19 polymorphisms; PCR-RFLP

Please cite this article as: Poopak B, Heidar M, Fallah P, Safari N, Rabieipour S, Amiri Z, Taghdisi Sh. Genetic Polymorphisms of CYP2C19 and Resistance to Clopidogrel Therapy among Iranian Patients Suffering from Ischemic Heart Disease. Res Mol Med. 2016; 4 (3): 41-46

\section{Introduction}

Clopidogrel and its combination with low-dose aspirin are currently recommended as an anti-platelet therapy to prevent ischemic events following coronary syndromes or stent placement $(1,2)$. However, $3-40 \%$ of the patients treated with clopidogrel show an impaired response to this treatment (3). It is reported that clopidogrel resistance has been recognized in patients exhibiting less platelet aggregation inhibition, with the value of dependence on the loading dose of clopidogrel and the methods used to assess non responsiveness $(3,4)$. Clopidogrel is a prodrug that its clinical efficacy looks to be a function of the amount of enzymatically derived thiol metabolite $(5,6)$. Clopidogrel is activated in two steps and CYP2C19 protein plays a dominant role in this chemical way. CYP2C19 protein is encoded by the CYP2C19 gene, which is located in chromosome 10. Variations of this gene may lead to the creation of the loss-of-function alleles, CYP2C19*2 andCYP2C19*3, and subsequently 
to the complete absence of the enzyme (8).

Genetic variants of CYP2C19 can occur as eitherheterozygous or homozygous alleles that cause the prevention of clopidogrel biotransformation to its active metabolite form. This seems to be an important indication of clopidogrel antiplatelet effect $(9,10)$ since it leads to reduction in in antiplatelet effect of clopidogrel.

Regarding the importance of CYP2C19 polymorphisms in clopidogrel therapy and considering its diverse prevalence rate in different geographical regions, the United States Food and Drug administration (FDA) has advised to consider CYP2C19 genotyping before administration of clopidogrel. The frequencies of these two alleles $(* 2 \& * 3)$ have been established in various countries. According to a number of studies, the frequency of CYP2C19*2 allele varies between 0.11 and 0.15 percent (11). Additionally, some other studies showed different frequencies of CYP2C19*3 alleles as 0.004 and $0.006(12,13)$.

In one of the studies done on Indian population, the frequencies of certain CYP2C19 genotypes, namely CYP2C19*1/*1, *1/*2, *2/*2,*1/*17,*17/*17, and $* 2 / * 17$, were evaluated as $16.1,31.0,18.4,20.7,1.2$, and $12.6 \%$, respectively. In this population, the prevalence of the defective CYP2C19*2 allele as well as the gain-of-function CYP2C19*17 allele, were found to be $40.2 \%$ and $17.9 \%$, respectively (14). In another study performed on 200 healthy Iranian population, the frequency of all CYP2C19*1/*3, CYP2C19*2/*3 and CYP2C19*3/*3 genotypes was $0 \%$ (15). Moreover, in a study by Han et al. (2015) genetic polymorphisms showed notable impact on clopidogrel response in Japanese patients (16).

However, there is no data available on the frequencies of CYP2C19 polymorphisms in Iranian population. The aim of this study was therefore to identify the prevalence of the CYP2C19*2 and *3 alleles in Iranian population and to compare it with the studies conducted in other parts of the world. The results will be helpful in determining the right dose of clopidogrel. Patients who are under or intended to get clopidogrel as the antiplatelet therapy may benefit from the results of this study.

In four previous studies carried out on Iranian population CYP2C19 genotyping was detected using PCR-RFLP protocol (17-20).

\section{Materials and Methods}

Subjects and study design

A cross sectional study was performed in which the cases were selected from patients attending the Cardiology clinic in Boo-Ali Hospital or private clinics across Iran between July 2010 and 2011. The study participants included 154 ischemic heart disease patients who were under maintenance therapy of $75 \mathrm{mg}$ clopidogrel as a daily dose for at least seven days. Patients were excluded if they had been treated with other antithrombotic drugs, such as heparin and glycoprotein inhibitors. Moreover, patients suffering from bleeding disorders or other coagulopathies were not included in the study. Among the study subjects, $75.3 \%$ of cases were on concomitant dual antiplatelet therapy with aspirin and clopidogrel. According to the opinion of physicians about cases that were treated by clopidogrel, sub-optimal responses could be seen in cases that did not respond to the drug and showed adverse cardiovascular events. In this study, there were some patients who were considered as clinically resistant to clopidogrel. Cases who had used inhibitors and clopidogrel simultaneously, were excluded.

Table 1. Primer sequences, amplification conditions of PCR and Interpretation of digested fragments according to base pair.

\begin{tabular}{|c|c|c|c|c|c|c|c|}
\hline \multirow{3}{*}{$\begin{array}{l}\text { Forward and reverse } \\
\text { primer sequences }\end{array}$} & \multicolumn{2}{|l|}{ Allele } & \multicolumn{3}{|c|}{ CYP2C19*2 } & \multicolumn{2}{|c|}{ CYP2C19*3 } \\
\hline & \multicolumn{2}{|c|}{ Forward primer } & \multicolumn{3}{|c|}{ CCAGAGCTTGGCATATTGTATC } & \multicolumn{2}{|c|}{ TCCAATCATTTAGCTTCACC } \\
\hline & \multicolumn{2}{|c|}{ Reverse primer } & \multicolumn{3}{|c|}{ GTAAACACACAACTAGTCAATG } & \multicolumn{2}{|c|}{ ACTTCAGGGCTTGGTCAATA } \\
\hline \multirow{3}{*}{$\begin{array}{l}\text { PCR amplification } \\
\text { conditions }\end{array}$} & Repeat & & 1 cycle & 45 cycle & & & 1 cycle \\
\hline & Time & & 7 minutes & $30 \mathrm{sec}$ & $30 \mathrm{sec}$ & $20 \mathrm{sec}$ & 5 minutes \\
\hline & Temperature & & 94 & 94 & 56 & 72 & 72 \\
\hline \multirow{3}{*}{$\begin{array}{l}\text { Interpretation of } \\
\text { digested fragments } \\
\text { according to base pair }\end{array}$} & Allele & $\begin{array}{l}\text { PCR fragment } \\
\text { (bp) }\end{array}$ & \multicolumn{3}{|c|}{ Normal fragment (bp) } & \multicolumn{2}{|c|}{ Mutant fragment (bp) } \\
\hline & $\mathrm{CYP} 2 \mathrm{C} 19 * 2$ & 322 & \multicolumn{3}{|l|}{$110+212$} & \multicolumn{2}{|l|}{322} \\
\hline & СYP2C19*3 & 266 & \multicolumn{3}{|l|}{$170+96$} & \multicolumn{2}{|l|}{260} \\
\hline
\end{tabular}




\section{Genotyping}

Blood samples $(5 \mathrm{~mL})$ were obtained from each patient. EDTA was added to each of these samples as anticoagulant. The cellular fraction was separated by centrifugation and DNA was extracted from the buffy-coat with a Fermentas kit. In next step, CYP2C19*2 and CYP2C19*3 genotyping was performed by PCR-restriction fragment length polymorphism (RFLP) method as described by Adithan et al. (21). Forward and reverse primer sequences for CYP2C19*2 and CYP2C19*3 PCR are presented in Table 1. PCR reactions were carried out in a $25 \mu \mathrm{L}$ reaction volume containing $100 \mathrm{ng}$ of DNA, $1 \mu \mathrm{L}$ of each primer, $2.5 \mu \mathrm{L}$ of $10 \mathrm{x}$ PCR buffer, $2.5 \mu \mathrm{L} \mathrm{MgCl} 2,0.5 \mu \mathrm{L}$ dNTPs $10 \mathrm{mM}$, and 1 unit of Taq DNA Polymerase.

The amplification conditions were performed according to Table $1.10 \mu \mathrm{L}$ of PCR products were digested with 10 units of BamHI restriction endonuclease for $\mathrm{CYP} 2 \mathrm{C} 19 * 3$ in $20 \mu \mathrm{L}$ reaction volume at $37{ }^{\circ} \mathrm{C}$, overnight and SmaI restriction endonuclease for $\mathrm{CYP} 2 \mathrm{C} 19 * 2$ in $20 \mu \mathrm{L}$ reaction volume at $30^{\circ} \mathrm{C}$, overnight. The digested PCR products were then separated on $6 \%$ polyacrylamide gel. The results were interpreted according to Table 1.

At the end, the PCR products of randomly selected homozygous and heterozygous mutant samples were sequenced for confirmation (14).

\section{Ethics Statement}

The study protocol was approved by the ethical committee of Boo-Ali Hospital and a written informed consent was signed by all participants.

\section{Statistical analysis}

The computer-based analysis program SPSS (Statistical Package for the Social Sciences, 12.0 for PC, SPSS, Inc., Chicago, Illinois) was used for statistical calculations in this study. Categorical variables were reported as counts (percentages), and continuous variables were reported as mean \pm SD . We tested differences between the groups applying Chi-square test for categorical variables (or Fisher exact test when any expected cell count was $<5$ for a $2 \times 2$ table) and unpaired Student t-test or one-way analysis of variance for continuous variables. In addition, the Kolmogorov-Smirnov test was used to assess normal distribution. A P-value $<0.05$ was considered significant.

\section{Results}

Baseline characteristics of the study population

A total of 154 patients were enrolled in this study including 85 (55.2\%) males and 69 (44.8\%) females. The average age was $59.4 \pm 12.9$ (SD) ranging from 18-81 years old. Furthermore, 116 (75.3\%) cases were on aspirin therapy. In $2.6 \%$ of these cases the aspirin dose was higher than $100 \mathrm{mg}$.

CYP2C19 status of the study population

The frequencies of wild type $(* 1 / * 1)$, mutated heterozygous $(* 2 / * 3, * 1 / * 2, * 1 / * 3)$ and mutated homozygous $(* 2 / * 2, * 3 / * 3)$ were evaluated as $72.7 \%$ (112 cases), $23.4 \%$ (36 cases) and 3.9\% (6 cases), respectively (Figure 2). Clinical resistance to clopidogrel was observed in 20 patients $(83.3 \%)$ with wild genotype and four patients (16.7\%) with mutated heterozygous cases (Figure 1).

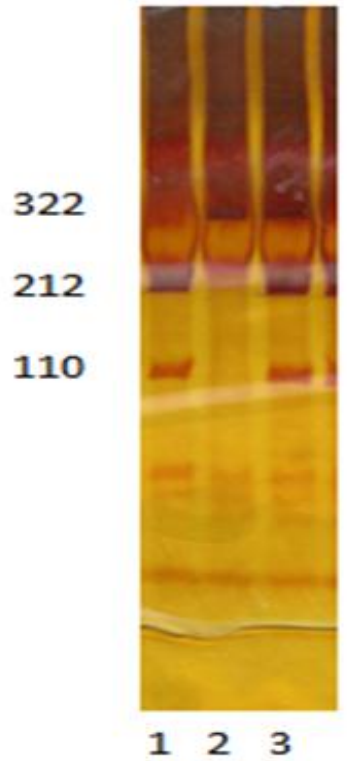

Figure 1. Polyacrylamide gel electrophoresis after polymerase chain reaction-restriction (CYP2C19*2). Line1: Normal fragment $(110,212)$, Line 2: Mutant fragment (322, homozygous), Line 3: Mutant fragment (110, 212, 322 heterozygous).

According to the results, 20 of 24 patients (83.3\%) who used clopidogrel had normal genotype and four (16.7\%) were heterozygous for CYP2C19*2.

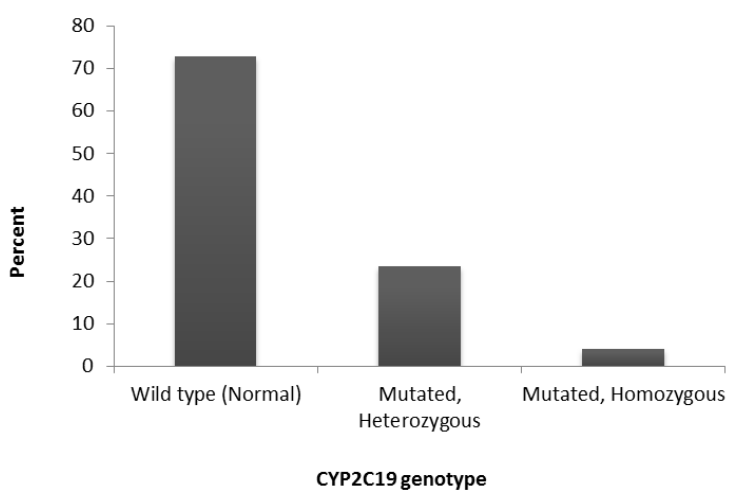

Figure 2. Relative frequency distribution of gene alterations in the study patients. 
Among those who had wild genotype, $78.9 \%$ were male and $21.1 \%$ were female. Moreover $100 \%$ of women and $78.9 \%$ of men had normal genotype and were not resistant to clopidogrel while $21.1 \%$ of men who were heterozygous were resistant to clopidogrel. Moreover, $100 \%$ of heterozygous cases were male (Figure 3). Furthermore, the Chi-square test results indicated no significant association between gender and resistance to clopidogrel.

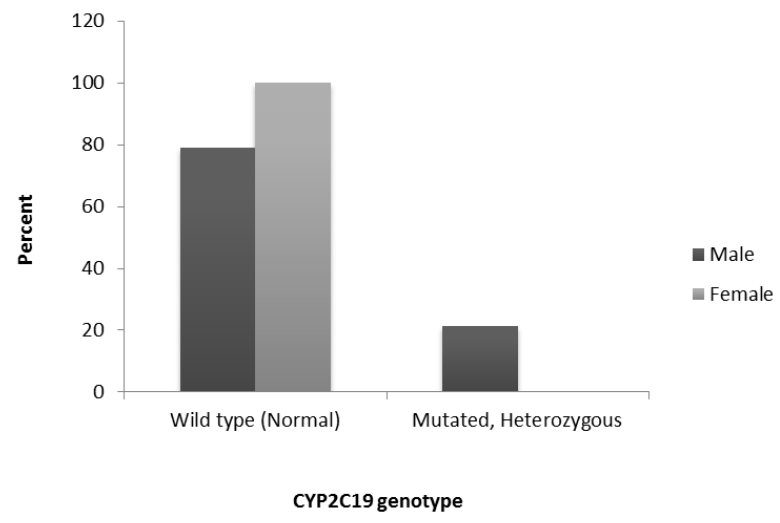

Figure 3. Frequency of clopidogrel resistance in male and female.

\section{Discussion}

The impact of CYP2C19 genetic variations on clopidogrel antiplatelet response has been documented in a number of studies $(22,23)$. The importance of genotyping CYP2C19 *2 and *3 has been highlighted by FDA. According to FDA recommendation antiplatelet therapy with clopidogrel must be done carefully in populations with a high prevalence of risk alleles (24).

Reduced CYP2C19 metabolism in intermediate and poor metabolizers decreases the maximum concentration of active metabolite by 30 to $50 \%$ resulting in lower platelet inhibition (25).

In March 2010, FDA announced that poor metabolizers of clopidogrel may not be fully protected from heart attack, stroke, and cardiovascular death. Molecular diagnostic tests can be used for determining the CYP2C19 genetic profile and identifying patients who are unable to convert passive clopidogrel to its actives forms (24).

In a recent meta-analysis and systematic review report, Snoep et al. concluded that among patients undergoing percutaneous intervention, one in every five people are likely to show non-responsiveness to clopidogrel therapy; these individuals are at an eightfold increased risk of developing an adverse clinical outcome (4).

In order to provide physicians with an estimation of the potential number of poor metabolizers among Iranian patients, we set out to study the prevalence of the CYP2C19*2 and *3 risk alleles in Iranian population.

In the present study, nearly $75.3 \%$ of the patients were on dual antiplatelet therapy with clopidogrel and aspirin. The results showed the prevalence of CYP2C19 *2 and*3 alleles were $23.4 \%$ and $3.9 \%$, respectively. The prevalence of these alleles in Caucasian population ranged from $0.11-0.16$ and $0.0-0.7$, respectively (26). These frequencies were $0.11 \%$ and $0.002 \%$, respectively in Egyptian population and $0.15 \%$ and $0.01 \%$, respectively in Israeli Jewish population (11). In addition, the prevalence of CYP2C19 *2 and *3 in Lebanese population were $0.13 \%$ and $0.03 \%$, respectively (27). The results of the present demonstrate that the application of the FDA recommendations may be useful in Iran more than other countries. Physicians must identify patients who are at high risk for atherothrombotic events when undergoing clopidogrel therapy and consider other antiplatelet medications or alternative dosing strategies in poor metabolizers (27).

There were a number of limitations to this study. Firstly, the study was performed as a nonrandomized, observational and single center study. Secondly, the plasma levels of the clopidogrel active metabolite could not be measured and also the genetic association with the pharmacokinetic aspects of this medication could not be evaluated. Thirdly, the study had no aim to evaluate the association between clinical outcomes and genetic polymorphisms of CYP2C19. Further studies with these aims are required to fill the gaps in knowledge.

\section{Acknowledgements}

We express our gratitude to all Payvand Clinical and Specialty Laboratory staffs who backed our work step by step and gave us access to their vast experience and reservoir of creative ideas. The authors would like to thank the staffs in department of cardiology, Boo-Ali hospital. The staffs in Tehran Medical Branch, Islamic Azad University, are also greatly acknowledged for their contributions to this project.

\section{Support/Funding}

All financial support was provided by Payvand Clinical and Specialty Laboratory.

\section{Conflict of Interest}

The authors declare that they have no conflict of interest in this work.

\section{References}

1. Patrono C, Bachmann F, Baigent C, Bode C, De Caterina R, Charbonnier B, et al. Expert consensus document on the use of 
antiplatelet agents the task force on the use of antiplatelet agents in patients with atherosclerotic cardiovascular disease of the European society of cardiology. Eur Heart J. 2004; 25(2):166-81. PMID: 14720534

2. Steinhubl SR, Berger PB, Mann JT, 3rd, Fry ET, DeLago A, Wilmer C, et al. Early and sustained dual oral antiplatelet therapy following percutaneous coronary intervention: a randomized controlled trial. JAMA. 2002; 288(19):2411-20.

3. Nguyen TA, Diodati JG, Pharand C. Resistance to clopidogrel: a review of the evidence. J Am Coll Cardiol. 2005; 45(8):1157-64. PMID: 15837243

4. Snoep JD, Hovens MM, Eikenboom JC, van der Bom JG, Jukema JW, Huisman MV. Clopidogrel nonresponsiveness in patients undergoing percutaneous coronary intervention with stenting: a systematic review and meta-analysis. Am Heart J. 2007; 154(2):221-31. PMID: 17643570

5. Frere C, Cuisset T, Morange PE, Quilici J, Camoin-Jau L, Saut $\mathrm{N}$, et al. Effect of cytochrome p450 polymorphisms on platelet reactivity after treatment with clopidogrel in acute coronary syndrome. Am J Cardiol. 2008; 101(8):1088-93. PMID: 18394438

6. Pereillo JM, Maftouh M, Andrieu A, Uzabiaga MF, Fedeli O, Savi P, et al. Structure and stereochemistry of the active metabolite of clopidogrel. Drug Metab Dispos. 2002; 30(11):1288-95. PMID: 12386137

7. Giusti B, Gori AM, Marcucci R, Saracini C, Vestrini A, Abbate R. Determinants to optimize response to clopidogrel in acute coronary syndrome. Pharmgenomics Pers Med. 2010; 3:33-50. PMID: 23226041

8. Subraja K, Dkhar SA, Priyadharsini R, Ravindra BK, Shewade DG, Satheesh S, et al. Genetic polymorphisms of CYP2C19 influences the response to clopidogrel in ischemic heart disease patients in the South Indian Tamilian population. Eur J Clin Pharmacol. 2013; 69(3):415-22. PMID: 22955794

9. Hulot JS, Bura A, Villard E, Azizi M, Remones V, Goyenvalle C, et al. Cytochrome P450 2C19 loss-of-function polymorphism is a major determinant of clopidogrel responsiveness in healthy subjects. Blood. 2006; 108(7):2244-7. PMID:16772608

10. Shuldiner AR, O'Connell JR, Bliden KP, Gandhi A, Ryan K, Horenstein RB, et al. Association of cytochrome P450 2C19 genotype with the antiplatelet effect and clinical efficacy of clopidogrel therapy. JAMA. 2009; 302(8):849-57. PMID: 19706858

11. Sameer AE, Amany GM, Abdela AA, Fadel SA. CYP2C19 genotypes in a population of healthy volunteers and in children with hematological malignancies in Gaza Strip. Can J Clin Pharmacol. 2009; 16(1):e156-62. PMID: 19193970

12. Aynacioglu AS, Sachse C, Bozkurt A, Kortunay S, Nacak M, Schröder $\mathrm{T}$, et al. Low frequency of defective alleles of cytochrome P450 enzymes 2C19 and 2D6 in the Turkish population. Clin Pharmacol Ther. 1999; 66(2): 185-92. PMID: 10460072

13. Mahmoudi Sabera M, Boroumandb M, Behmanesha M Investigation of $\mathrm{CYP} 2 \mathrm{C} 19$ allele and genotype frequencies in Iranian population using experimental and computational approaches. Thromb Res. 2014; 133(2): 272-5. PMID: 24315317

14. Anichavezhi D, Chakradhara Rao US, Shewade DG, Krishnamoorthy R, Adithan C. Distribution of CYP2C19*17 allele and genotypes in an Indian population. J Clin Pharm Ther. 2012 Jun; 37(3):313-8. PMID: 21916910

15. Zand N, Tajik N, Hoormand M, Salek Moghadam A and Milanian I. Allele Frequency of CYP2C19 Gene Polymorphisms in a Healthy Iranian Population. Iranian J Pharmacol Ther. 2005; 4(2): 124-128

16. Yan Han Y, Lv HH, Liu X, Dong Q, Yang XL, Li SX, et al. Influence of Genetic Polymorphisms on Clopidogrel Response and Clinical Outcomes in Patients with Acute Ischemic Stroke CYP2C19 Genotype on Clopidogrel Response. CNS Neurosci Ther. 2015; 21(9): 692-7. PMID: 26177117

17. Azarpira N, Namazi S, Hendijani F, Banan M, Darai M. Investigation of allele and genotype frequencies of CYP2C9, CYP2C19 and VKORC1 in Iran. J Mol Diagn. 2010; 62(4): 74046. PMID: 20885015

18. Negin Zand N, Tajik N, Moghaddam AS, Milanian I. Genetic polymorphisms of cytochrome P450 enzymes 2C9 and 2C19 in a healthy Iranian population. Clin Exp Pharmacol Physiol. 2007; 34(4): 102-105. PMID: 17201743

19. Zendehdel N, Biramijamal F, Hossein-Nezhad A, Zendehdel N, Sarie H, Doughaiemoghaddam M, et al. Role of Cytochrome P450 2C19 Genetic Polymorphisms in the Therapeutic Efcacy of Omeprazole in Iranian Patients with Erosive Reflux Esophagitis. Arch Iran Med. 2010; 13(5): 406. PMID: 20804307

20. Shahabi-Majd N, Hashemi-Sotehoh MB, Habashi B , Shiran MR. Frequencies of two CYP2C19 defective alleles (CYP2C19*2, and *3) among Iranian population in Mazandaran Province. Res Mol Med. 2013:1(1): 17-21.

21. Adithan C, Gerard N, Vasu S, Rosemary J, Shashindran CH, Krishnamoorthy R. Allele and genotype frequency of CYP2C19 in a Tamilian population. Br. J. Clin. Pharmacol. 2003; 56(3):331-3. PMID: 12919183

22. Simon T, Verstuyft C, Mary-Krause M, Quteineh L, Drouet E, Meneveau N, et al. Genetic determinants of response to clopidogrel and cardiovascular events. N Engl J Med. 2009 Jan 22; 360(4):363-75. PMID: 19106083

23. Hulot JS, Collet JP, Silvain J, Pena A, Bellemain-Appaix A, Barthelemy $\mathrm{O}$, et al. Cardiovascular risk in clopidogrel-treated patients according to cytochrome P450 2C19*2 loss-of-function allele or proton pump inhibitor coadministration: a systematic meta-analysis. J Am Coll Cardiol. 2010; 56(2):134-43. PMID: 20620727

24. FDA Drug Safety Communication: Reduced effectiveness of Plavix (clopidogrel) in patients who are poor metabolizers of the drug [Internet]. Fda.gov. 2016 [cited 2 June 2016]. Available from: http://www.fda.gov/Drugs/DrugSafety/PostmarketDrugSafetyInfor mationforPatientsandProviders/ucm203888.htm.

25. Wei W, Fang L, Wang N, Zhang T, Zeng JB, Lin MT. Prevalence of CYP2C19 polymorphisms involved in clopidogrel metabolism in Fujian Han population. Zhonghua Yi Xue Yi Chuan Xue Za Zhi. 2012; 29(4):420-5. PMID: 22875498

26. Scott SA, Sangkuhl K, Shuldiner AR, Hulot JS, Thron CF, Altman RB, et al. PharmGKB summary: very important pharmacogene information for cytochrome P450, family 2, subfamily C, polypeptide 19. Pharmacogenet Genomics. 2010; 22(2): 159-65. PMID: 22027650

27. Djaffar Jureidini I, Chamseddine N, Keleshian S, Naoufal R, 
Zahed L, Hakime N. Prevalence of CYP2C19 polymorphisms in the Lebanese population. Mol Biol Rep. 2011; 38(8):5449-52. PMID: 21380557 